\title{
Social-Media Addiction Among Late Adolescents: Self- Esteem and Narcissism as Predictor
}

\author{
Zoya Zurafa ${ }^{1}$ Fransisca Iriani R. Dewi ${ }^{*}$ \\ ${ }^{1}$ Faculty of Psychology, Universitas Tarumanagara, Jl. Letjen S. Parman No. 1, West Jakarta 11440, Indonesia \\ *Corresponding author. Email: fransiscar@fpsi.untar.ac.id
}

\begin{abstract}
Social media addiction is the compulsive behavior in the use of social media so that it becomes the symptom of addictive behavior. Adolescents is one of the biggest users of social media and smartphones. This study was conducted to examine the effect of self-esteem and narcissism on social-media addiction among late adolescents. Participants who took part in this study were 374 people as active users of social media and at least use social media for more than 2 hours per day. The measuring instruments used are the Rosenberg SelfEsteem Scale, the Narcissistic Personality Inventory-Likert, and the Bergen Social-Media Addiction Scale. To prove the hypothesis, we used multiple linear regression analysis technique. The results show that there is a significant influence on self-esteem and narcissism on social media addiction among late adolescents, with the contribution of $11.3 \%$ from the two variables, namely self-esteem and narcissism on social-media addiction among late adolescents $\left(\mathrm{R}^{2}=0.113, \mathrm{p}=0.00,<0.05\right)$.
\end{abstract}

\section{Keywords: Social-media addiction, Adolescene, Self-esteem, Narcissism}

\section{INTRODUCTION}

The use of the internet, especially social media, is increasingly sought by people all over the world. There are 2.3 million of active social media users in the world [1] and as many as $18.9 \%$ of people in Indonesia use social media as the main reason for using the internet [2]. Social media is a medium for interacting with its users, such as Facebook, Instagram, Whatsapp, Twitter, Youtube, and others [3][4]. The benefits of social media can be used as a medium for interaction, communication, sharing of ideas and information, entertainment, and self-development [3] [4]. The many benefits of using social media make social media popular among many people.

One of the fans of social media are adolescents. They are one of the biggest users of social media and smartphones [5]. Adolescents use social media related to developmental stages and as a form of self-image and show their identity as a need for self-discovery [6]. The theory of psychosocial development developed by Erikson has a stage of identity versus identity conflict, where adolescents begin to explore self-identity and develop themselves [7]. By using social media, adolescents can participate in various kinds of activities according to their interests and can find their identity [8]. Because of related things on the development stages and needs for using social media, adolescent become the right participant for the research.

Apart from the benefits, there are also bad effects from using social media. The impact of social media addiction behavior is that someone will feel anxious if they stop using social media and disconnect from themselves [9]. The results from previous studies show that teens spend one to eight hours on internet access per day. They feel sad and angry when being disconnected from the world, and feel that something is missing when they cannot access the internet [10]. If the use of social media interferes with daily activities, it can lead to addiction.

The purpose of doing this research is for knowing the influence of self-esteem and narcissism on social media addiction among late adolescent.

\subsection{Related Work}

Based on the explanation from previous research, it can be concluded that there is a relationship among self-esteem, narcissism, and social media addiction. There is also a research that shows inconsistencies and needs to be redone. The previous studies were mostly carried out abroad and could not be generalized to the subjects in Indonesia. In addition, this research was conducted during a pandemic where there is a surge in social media use [11]. The author will test whether there is an influence among these three variables.

\subsection{Our Contribution}

The theoretical benefit of this research is to become additional knowledge to the pre-existing knowledge, information, theory and data, and to contribute to the 
knowledge about self-esteem, narcissism, and social-media addiction among late adolescents.

The practical benefits of this research are adding insight and experience to researchers and adolescent of social media users in discussing about self-esteem, narcissism, and social-media addiction.

\subsection{Paper Structure}

This paper is divided into four sections. Section 1 consist of research background and the goal of this study. In Section 2 (Methods), participants of the study, measurement used, data analysis plan is discussed. Section 3 presents the analysis result and findings of this study, and its implication. Lastly, Section 4 presents the conclusion of this paper as well as direction for future research.

\section{BACKGROUND}

\subsection{Social-Media Addiction}

Social media addiction is a compulsive behavior in the use of social media so that the symptoms of addictive behavior appear [12]. There are six components of addiction, namely salience, which is the behavior of a person who is focused on something. Mood modification, namely carrying out these activities to get a pleasant feeling. Tolerance, which is when someone increases certain activities to get the same feeling when they firstly use them. Withdrawal symptoms, when the activity is stopped, a person will experience physical and psychological discomfort. Conflict is when a person experiences interpersonal and intrapersonal problems due to using social media and relapse, namely repeating thebehavior [13].

Adolescents who experience social-media addiction have problems forming relationships and social interactions [14]. Awkwardness, shyness, and less ability to express themselves when interacting with others are the characteristics of low self-esteem [15]. Someone with low self-esteem tends to have difficulty interacting and communicating directly with people [21]. This means that self-esteem can be a predictor of social-media addiction behavior.

\subsection{Self-Esteem}

Self-esteem is a comprehensive evaluation of self that includes positive and negative attributes and refers to selfesteem [12][7]. The results of previous studies suggest that there is a relationship between self-esteem and socialmedia addiction [16]. There is also a research showing that there is no correlation between self-esteem and social media use [17].

\subsection{Narcissism}

The characteristics of personality traits such as narcissism tend to be related to social-media use [18]. Narcissism is a personality trait characterized by a sense of admiration for one self, always feeling like the best and wanting to be the center of attention [19]. There are dimensions of the narcissism personality, namely having a sense of leadership and dominating (authority), having high selfconfidence in their abilities (self-sufficiency), feeling themselves the best among people (superiority), like being the center of attention and sensation-seekers (exhibitionism), using other people to increase self-esteem (exploitativeness), (vanity), and have a feeling of wanting to be respected and in need of power (entitlement) [20].

The relationship between narcissism and social-media use has been a topic of research since the inception of social media sites, but evidence of a link between narcissism and social media-use problems is still inadequately proven and poorly explained [11]. Therefore, the authors want to reexamine the relationship between social-media use and narcissism variables. The results of previous studies stated that there was no relationship between someone with narcissism and problematic social-media use [22]. Furthermore, there is a relationship between narcissism and problematic use of social media which will lead to addiction [5].

\subsection{Adolescent}

Adolescence is a transitional period between childhood and adulthood. There are changes in the biological, cognitive, and socio-emotional aspects. This change is to prepare for the adult stage. Early adolescence ranges in age 10-13. At this time puberty begins. Meanwhile, the late adolescence stage appears at the age of 17 - late 19 years. During this time there was an interest in career, exploration of identity, and starting dating. Missing in goal achievement and self-identity caused identity confusion [7]. They withdraw from social life, lose their identity, insecure, and psychologically delay maturity [7].

\section{METHODS}

The criteria for the participants of this study were: women and men aged 17-19 years, active users of social media, using social media for more than 2 hours per day, had high level on social media addiction, medium to low level on self-esteem, and medium to high level on narcissism. This study does not provide a limit onrace, religion, ethnicity, social status, and latest education. For the sampling technique, we used the non-probability sampling, namely purposive sampling. Initially, there were 395 participants who participated in this study. After screening based on the specified criteria, 95 participants were eligible to be processed as research participants. Based on demographic data, it was found that most participants were women $(93.7 \%)$ using social media as many as 1 - 4 types $(81.7 \%)$, and the duration of social-media use is $>8$ hours 
per day $(40.0 \%)$. Research type is quantitative nonexperimental. Data collection used a research questionnaire which was conducted online. To measure the variable of self-esteem, we used the Rosenberg SelfEsteem Scale (RSES) which was developed by Morris Rosenberg in 1965 and an adaptation of the translation into Indonesian was carried out. This measuring instrument consists of 20 items with a 5-point Likert scale.

To measure the narcissism variable, used the Narcissistic Personality Inventory - Likert (NPI-L) developed by Brittany Gentile [15] and has been translated into Indonesian. This measuring instrument consists of 40 items with a 5-point Likert scale.

To measure social-media addiction variables, the Bergen Social-Media Addiction Scale (BSMAS) was used, which was developed by Andreassen [23] and has been translated into Indonesian. This measuring instrument consists of 6 items with a 5-point Likert scale.

To test the multiple linear regression hypothesis, there are several conditions that must be met. The researcher first carried-out a normality test using residual data. The result is $\mathrm{p}>0.05$ and it means that the data is normally distributed. The researcher also conducted a linearity test using a scatterplot matrix. The results show that the data is linear, because there is a slashline in the scatterplot matrix table. Furthermore, the researchers conducted a multicollinearity test on the data. Data processing shows that all variables have a tolerance value above 0.1 and a VIF value below 10 , so it can be concluded that there is no multicollinearity in the data. Finally, the researcher conducted a heteroscedaticity test by looking at the scatterplot graph. The results show that the dots spread randomly and do not form a specific pattern, so it can be concluded that the data does not have heteroscedasticity.

The analysis of hypotheses in multiple linear regression was conducted to determine whether there is a simultaneous influence of self-esteem and narcissism on social-media addiction. The results show that the value of $\mathrm{R}$ Square is 0.113 , meaning that price and narcissism contribute $11.3 \%$ to social-media addiction and $88.7 \%$ is influenced by other factors not included in this study.

\section{FINDINGS AND DISCUSSIONS}

Table 1 Data Analysis Results

\begin{tabular}{cccccc} 
Variable & R Square & Adjusted R Square & $\begin{array}{c}\text { Standardized Coefficients } \\
\text { Beta }\end{array}$ & Sig $(p)$ \\
\hline $\begin{array}{c}\text { Self-esteem, } \\
\text { Narcissism }\end{array}$ & 0.199 & 0.182 & -0.201 & -2.124 & 0.036 \\
\cline { 2 - 5 } & & & 0.436 & 4.599 & 0.000 \\
\hline
\end{tabular}

Several additional analyses were performed on the control data. Researchers used the independent-sample t-test to compare self-esteem, narcissism, and social-media addiction in terms of gender. The results showed that there was no significant difference in self-esteem, $p=0.06$ (> $0.05)$. Narcissism when viewed from gender shows that there was no significant difference, because $p=0.22$ (< $0.05)$. Social media addiction in terms of gender shows that there was no significant difference, because $\mathrm{p}=0.08$ $(<0.05)$.

Researchers used one-way ANOVA to compare selfesteem, narcissism, and social-media addiction in terms of duration of social-media use. The results showed that there was no significant difference in self-esteem $(\mathrm{p}=0.93$, > $0.05)$. Narcissism in terms of duration of social-media use shows that there was no significant difference $(p=0.57)$. Social-media addiction in terms of duration of socialmedia use shows that there is a significant difference with the highest average duration ( $>8$ hours) $(\mathrm{M}=4.31, \mathrm{p}=$ $0.00)$.

This study was conducted to determine the effect of selfesteem and narcissism on social-media addiction among late adolescents. Based on the results of data analysis, there is an effect of self-esteem and narcissism on social media addiction by $19.9 \%$. The results of the study indicate that hypothesis 1 is accepted. The results showed that there was a significant influence of self-esteem and narcissism on social-media addiction among late adolescents. This is in line with previous research which stated that self-esteem affects the emergence of social media addiction, because someone with low self-esteem will avoid direct interaction and use of social media as a forum for social interaction [21]. A person with low selfesteem will feel dissatisfied with him/herself, anxious when interacting with other people, and have difficulty expressing him/herself when socializing [15].

Other studies have also shown that self-esteem has a relationship with social-media addiction [16]. This means that people with low self-esteem tends to have socialmedia addiction to fulfill their needs in expressing themselves and interacting on social media.

Previous studies have suggested narcissism has an influence on social-media addiction [24][25]. The results suggest that narcissism causes an increase in the aspects of social-media addiction, namely mood modification, withdrawal, and tolerance [25]. Other studies have shown that someone with high level of narcissism will use social media for a long time, feel dependent on social media and cannot live without social media [26]. The behavior shown illustrates the criteria for social-media addiction, so that it can support the results of this study.

Narcissism involves the behavior of seeking the attention of others or wanting to be liked [16], therefore they use social media as a forum to fulfill their needs to be the 
center of attention and want to be liked by people. Someonewho has a high level of narcissism tends to post more often on social media, have lots of friends on social media, and spend a lot of time using social media [27]. The behavior of someone who spends a lot of time on social media according to the criteria for social-media addiction, namely tolerance. In addition, a person with narcissism usess ocial media for self-promotion and fulfills his/her need for self-improvement [27].

Researchers also conducted additional analysis in form of the test for differences in self-esteem and gender. The results show that it is not significant, meaning that there is no difference. This is not in line with previous research which states that there are differences in the level of selfesteem between women and men [24]. The test result for the difference between narcissism and gender was also not significant, meaning that there was no difference. These results are not in line with previous studies which showed that the rate of narcissism in men will be higher than that in women [27]. The test for differences in social-media addiction by gender shows that there are no significant differences with the highest mean for women. These findings are not in line with the research which stated that women tend to be more at risk of developing addictive behavior in social-interaction activities, whereas men tend to be more at risk of developing addictive behavior in online games [24].

Furthermore, the test for differences in self-esteem variables with duration of social-media use was not significant. The duration of social-media use can be said to be the intensity of use. From previous research, it was stated that there was a relationship between the intensity of social media use and self-esteem [28]. Between narcissism and the duration of social-media use, there is no significant difference, while between social-media addiction and the duration of social-media use, there is a significant difference with the highest average duration of use $>8$ hours. This is in line with the research which stated that someone who uses social media for a long time tends to be at risk of experiencing social-media addiction [29]. The excessive use of social media tends to lead to addiction [30]. Thus, it can be concluded that social-media addiction can be influenced by the long duration of social-media use, whereas in narcissism there is not much supporting evidence.

\section{CONCLUSIONS}

The results of research data processing show that there is a simultaneous influence of self-esteem and narcissism on social-media addiction. We performed several additional analyses of the control data. First, test for gender difference with social-media addiction, self-esteem, and narcissism. The results show that there are no significant differences. Second, we tested the difference between the duration of social-media use and social-media addiction. The results show that there are significant differences and the highest average is found at a duration of $>8$ hours.
For further research, researchers suggest using a better measuring tool for measuring social-media addiction. Perhaps it can be seen from how many items that represent the aspects of social media addiction. Researchers also suggest considering the selection of measuring instruments and the number of items from the questionnaire so that the subject does not get tired when filling-out and causing bias. In addition, research can be carried out extensively so that the number of subjects can be greater. Another suggestion is for future research to use control data for more specific criteria such as employment, education, and others. This can be done so that the research has an element of novelty.

Suggestions related to practical benefits are for late adolescents, it is hoped that reading this research can provide an awareness that social media has positive and negative impacts. Late adolescents can be more aware when using social media so as not to become addicts and abuse social media. In addition, late adolescents who use social media can benefit positively from this research and be more careful when using social media so as not to have a negative psychological impact.

\section{REFERENCES}

[1] Kircaburun, K. (2016). Self-esteem, daily internet use and social media addiction as predictors of depression among turkish adolescents. Journal of Education and Practice. 7(24), 64-72. retrieved from https://files.eric.ed.gov/fulltext/EJ1112856.pdf

[2] Asosiasi Penyelenggara Jasa Internet Indonesia. (2018). Penetrasi \& Profil Perilaku Pengguna Internet Indonesia. Downloaded from https://apjii.or.id/survei

[3] Manning, J. (2014). Definition and classes of social media. Encyclopedia of Social Media and Politics. 1158-1162. Thousand Oaks, CA: Sage.

[4] O’Keefe, G. S., Clarke-Pearson, K. (2011). Clinical Report - The Impact of Social Media on Children, Adolescents, and Families. American Academy of Pediatrics, 127(4), 800-804. doi:10.1542/peds.20110054

[5] Hawk, S. T., van den Eijnden, R. J. J. M., van Lissa, C. J., \& terBogt, T. F. M. (2018). Narcissistic adolescents' attention-seeking following social rejection: Links with social media disclosure, problematic social media use, and smartphone stress. Computers in Human Behavior. DOI: 10.1016/j. chb.2018.10.032

[6] Esa, N. D. (2018). Hubungan antara kecenderungan narsisme dengan motif memposting foto selfie di 
Instagram pada remaja di SMA Negeri 1 Sidayu Gresik. Psikosains, 13(1), 44-56.

[7] Santrock, J. W. (2016). Adolescence: An introduction. Dubuque, Iowa: Wm. C. Brown

[8]Gerwin, R. L., Kaliebe, K., \& Daigle, M. (2018). The interplay between digital media use and development. Child and Adolescent Psychiatric Clinics of North America, 27(2), 345-355. DOI: 10.1016/j. chc.2017.11.002

[9] Andreassen, C. S., Billieux, J., Griffiths, M. D., Kuss, D. J., Demetrovics, Z., Mazzoni, E., et al. (2016). The relationship between addictive use of social media and video games and symptoms of psychiatric disorders: A large- scale cross-sectional study. Psychology of Addictive Behaviors, 30(2), 252- 262. DOI: $10.1037 / \mathrm{adb} 0000160$

[10] Kurniasih, N. (2017). Internet addiction, lifestyle or mental disorder? A phenomenological study on social media addiction in Indonesia. KnE Social Sciences, 2(4), 135-144. https://doi.org/10.18502/kss. v2i4.879

[11] Singh, S., Dixit, A., \& Joshi, G. (2020). Is compulsive social media use amid COVID-19 Pandemic addictive behavior or coping mechanism? Asian Journal Psychiatrist. 54, 102290. DOI: 10.1016/j.ajp.2020.102290

[12] Hawi, N. S., \& Samaha, M. (2017). The relations among social media addiction, self-esteem, and life satisfaction in university students. Social Science Computer Review, 35(5), 576-586. DOI: 10.1177/ 0894439316660340

[13] Griffiths, M. D., \&Kuss, D. (2017). Adolescent social media addiction (revisited). Education and Health, 35(3), 49-52.

[14] Oberst, U., Wegmann, E., Stodt, B., Brand, M., \& Chamarro, A. (2017). Negative consequences from heavy social networking in adolescents: The mediating role of fear of missing out. Journal of Adolescence, 55, 51-60. DOI: 10.1016/j.adolescence.2016.12.008

[15] Febrina, T. D., Suharso, P. L., \& Saleh, A. Y. (2018). Self-esteem remaja awal: Temuan baseline dari rencana program self-instructional training Kompetensi diri. Jurnal Psikologi Insight, 2(1),43-56.

[16] Malik, S., \& Khan. M. (2015). Impact of facebook addiction on narcissistic behavior and students. Journal of the Pakistan Medical Association, 65(3), 260-263.
[17] Ayas, T. \& Horzum, M. B. (2013). Relation between depression, loneliness, self- esteem and internet addiction. Education, 133(3), 283-290.

[18] Ross, C., Orr, E. S., Sisic, M., Arseneault, J. M., Simmering, M. G., \& Orr, R. R. (2009). Personality and motivations associated with Facebook use. Computers in Human Behavior, 25(2), 578-586. DOI: 10.1016/j. chb.2008.12.024

[19] Bushman, B. J., \& Baumeister, R. F. (1998). Threatened egotism, narcissism, self- esteem, and direct and displaced aggression: Does self-love or self-hate lead to violence? Journal of Personality and Social Psychology, 75(1), 219-229.

[20] Raskin, R., \& Terry, H. (1988). A principalcomponents analysis of the narcissistic personality inventory and further evidence of its construct validity. Journal of Personality and Social Psychology, 54(5), 890-902.

[21] Casale, S., \&Banchi, V. (2020). Narcissism and problematic social media use: A systematic literature review. Addictive Behaviors Reports, 11. DOI: 10.1016 /j.abrep.2020.100252

[22] Casale, S., Fioravanti, G., \& Rugai, L. (2016). Grandiose and vulnerable narcissists: Who is at higher risk for social networking addiction? Cyberpsychology, Behavior, and Social Networking, O0(0), 1-6. DOI: 10.1089/cyber.2016.0189

[23] Andreassen, S. C. (2015). Online social network site addiction: A comprehensive review. Technology and Addiction. (2), 175-184. DOI 10.1007/s40429-0150056-9

[24] Andreassen, C. S., Pallesen, S., \& Griffiths, M. D. (2017). The relationship between addictive use of social media, narcissism, and self-esteem: Findings from a large national survey. Addictive Behaviors, 64, 287293. DOI: 10.1016/j.addbeh.2016.03.006

[25] Choi, Y., (2018). Narcissism and social media addiction in workplace. The Journal of Asian Finance, Economics, and Bussiness, 5(2), 95-104.

[26] Błachnio, A., Przepiorka, A., \&Rudnicka, P. (2016). Narcissism and self-esteem as predictors of dimensions of Facebook use. Personality and Individual Differences, 90, 296-301. DOI: 10.1016/j. paid.2015.11.018

[27] McCain, J., \& Campbell, W. K. (2016). Narcissism and social media use: A meta- analytic review. 
Psychology of Popular Media Culture, 7(3), 308-327.

DOI: $10.1037 /$ ppm0000137

[28] Evelin, Adishesa, M. S. (2020). Hubungan intensitas penggunaan Instagram dan self-esteem pada remaja. Mind Set, 11(1), 26-36.

[29] Al-Menayes, J. J. (2015). Dimensions of social media addiction among university students in Kuwait. Psychology and Behavioral Sciences. 4(1), 23-28. DOI: 10.11648/j.pbs.20150401.14

[30] Kuss, J. D., \& Griffiths, M. D. (2017). Social networking sites and addiction: Ten lessons learned. International Journal of Environmental Research and Public Health. DOI: 10.3390/ijerph14030311. Downloaded from http://irep.ntu.ac.uk/id/eprint/31776/ 1/PubSub9230_Griffiths.pdf 